\title{
Retos y perspectivas para el cooperativismo mexicano
}

\author{
Graciela Lara Gómez ${ }^{1}$ \\ Universidad Autónoma de Querétaro \\ Carla Carolina Pérez Hernández² \\ Universidad Autónoma del Estado de Hidalgo
}

Sumario: I. Introducción. II. La relevancia de las cooperativas. III. El cooperativismo mexicano. 3.1. Las cooperativas en las entidades federativas. 3.2. Clases de cooperativas y sus características. 3.2.1. Las sociedades cooperativas de consumo. 3.2.2. Las sociedades cooperativas de producción. 3.2.3. Las sociedades cooperativas de ahorro y préstamo. IV. Retos y perspectivas. V. Conclusiones. VI. Bibliografía. VII. Anexo legislativo.

Resumen. Considerando la relevancia de las cooperativas en el contexto internacional y nacional, se analizan los retos y perspectivas que deben afrontar las cooperativas en México. Para tal efecto se destacan los beneficios de cumplir con el mandato constitucional de promover la existencia de las cooperativas, así como los aspectos legales que impulsan o limitan su fortalecimiento y expansión. También se aborda la situación sanitaria actual y cómo las diferentes experiencias de las cooperativas de consumo, producción y de ahorro y préstamo contribuyen en la atención de los desafíos para sostener las experiencias locales, permaneciendo en el mercado y dando continuidad a los beneficios sociales. Por lo que se propone que las cooperativas deben ser el instrumento de cambio que conduzca a las mejoras económicas y sociales para todos.

Palabras clave: desafíos, perspectivas, cooperativas.

Abstract. Taking into account the relevance of cooperatives in the international and national context, the challenges and perspectives that cooperatives must face in Mexico are analyzed. For this purpose, the benefits of complying with the constitutional mandate to promote the existence of cooperatives are

1 Doctora y Profesora-Investigadora de tiempo completo. Universidad Autónoma de Querétaro.

2 Doctora y Profesora-Investigadora de tiempo completo. Universidad Autónoma del Estado de Hidalgo. 
highlighted, as well as the legal aspects that promote or limit their strengthening and expansion. It also addresses the current health situation and how the different experiences of the consumer, production and savings and loan cooperatives contribute to addressing the challenges to sustain local experiences, remaining in the market and continuing social benefits. Therefore, it is proposed that cooperatives should be the instrument of change that leads to economic and social improvements for all.

Keywords: challenges, prospects, cooperatives. 


\section{Introducción}

El paradigma económico dominante ha demostrado su fracaso, irguiéndose como el icono de la desigualdad y la injusticia, favoreciendo el enriquecimiento de unos cuantos y la imposibilidad de la mayoría para acceder a mejores niveles de vida. Esto pone de manifiesto la urgencia de encontrar formas éticas de progreso económico y social, lo que implica recordar que vivimos en un mundo con recursos limitados y que esos recursos se encuentran en manos de unos pocos. Por lo que hace falta pugnar por sociedades más incluyentes y equitativas, que atiendan a la adecuada convivencia entre los ciudadanos, con pautas que promuevan el respeto de los derechos fundamentales, la cultura, el cuidado del entorno natural y la sana convivencia.

En este capítulo se da respuesta al cuestionamiento ¿cuáles son los retos a los que se enfrentan las cooperativas en el contexto mexicano y cómo deberán impulsarse iniciativas que los atiendan? De manera que, en principio se discute sobre la preeminencia de las cooperativas en el contexto mundial, para luego mostrar las características del cooperativismo en el nivel nacional, se enriquece este apartado con la estadística vigente sobre la presencia de las cooperativas en las entidades federativas, posteriormente, se analizan las tres clases de cooperativas y se mencionan ejemplos de organizaciones influentes en el contexto local, para enseguida dar paso a los retos que se afrontan y los escenarios viables para el desarrollo de estas. Los resultados muestran la realidad del cooperativismo en México, los desafíos que deben atenderse, y lo que hace falta construir para una apropiada participación de los diferentes actores políticos y sociales.

Finalmente, se cierra con las conclusiones, donde se reflexiona en torno a las pautas internacionales que pueden ser adoptadas por el Estado a través de sus políticas públicas, para generar un espacio propicio para el desarrollo de las cooperativas.

\section{La relevancia de las cooperativas}

Entre los estudiosos del tema se ha coincidido que las cooperativas tienen un rol positivo para la sociedad, ya que como lo ha señalado Martínez Charterina (41-42), desde los organismos internacionales se han trazado líneas de acción que han seguido dichas sociedades, tales como: el desarrollo de los pueblos, la educación 
universal y la satisfacción de las necesidades fundamentales. Con tales directrices, las cooperativas desde hace tiempo, han venido ayudando a la satisfacción de necesidades básicas como la vivienda, la salud, el fomento de la educación formal, además de que promueven el cuidado del medio ambiente, la equidad de género, la atención de la juventud y la niñez, así como temas relacionados con la justicia y la paz.

Con los evidentes beneficios que surgen del accionar cooperativo, es momento de escuchar las voces que atribuyen al capitalismo y sus procesos globalizadores, las grandes diferencias económicas y sociales que prevalecen entre la población. Las grandes brechas que han surgido como consecuencia del modelo económico dominante, han sido influidas por los procesos globalizadores, pero no puede ignorarse que con la globalización también surgen beneficios. En este sentido, Stiglitz (13) opina que no hay una sola forma de capitalismo, pues existen variantes en la economía de mercado, lo que hace que el problema no sea la globalización, sino la manera en cómo los países la han gestionado, dado que existen sociedades con sistemas sanitarios y educativos sobresalientes y una menor desigualdad.

En este sentido, el cooperativismo se presenta como una alternativa que posee fundamentos éticos y que ha confirmado que se puede coexistir eficientemente en la economía de mercado, desde una perspectiva incluyente, ya que a través de su modelo empresarial se involucra a las personas en diferentes roles (trabajador, consumidor, productor, propietario), por lo que el modelo cooperativo puede ser el contrapeso al modelo económico dominante.

Es un hecho que las cooperativas desempeñan una función central en el desarrollo local, ya que por su medio es posible fomentar diversas actividades para el beneficio de las personas, las que con objetivos comunes, se organizan en torno a la gestión empresarial, que no tiene como finalidad principal la maximización de la renta, sino la satisfacción de metas económicas y sociales. Asimismo, las cooperativas contribuyen al bienestar de las comunidades, favoreciendo la inserción social y laboral entre los sectores más desamparados, mitigando la marginación y pobreza a través de la producción y el consumo de bienes o servicios, así como con el fomento del ahorro y crédito.

En consecuencia, resulta interesante destacar los avances reportados por la Alianza Cooperativa Internacional $(A C I)$, los que revelan que la presencia de las cooperativas en el contexto mundial, ha tenido un significativo impacto a escala local e internacional, dado que existe una 
substancial diferencia entre tales sociedades y los negocios tradicionales (de capitales). Las cooperativas basan su actuación en principios y valores éticos, con un enfoque en el bienestar de las personas, son democráticas y el énfasis de sus actividades es la satisfacción de necesidades comunes. Mientras que las empresas de capitales o tradicionales, buscan la maximización de su aportación de capital, a través de la obtención de dividendos, sin que sean trascendentes los beneficios de tipo social o ambiental.

Datos adicionales indican que el $12 \%$ de la población mundial se encuentra vinculada a las 3 millones de cooperativas que operan en el mundo $(\mathrm{ACl}, 1)$. Por su parte, la Organización Internacional del Trabajo (OIT, 2) asevera que la renta agregada de las 300 empresas cooperativas más importantes a nivel internacional asciende a 1,6 billones de USD, cantidad equivalente al Producto Interno Bruto de la nación española, que es la novena economía mundial. Además el organismo señala que cerca de 1000 millones de personas están vinculadas con las cooperativas, ya sea como socios, clientes, empleados o participantes; además de que por lo menos 100 millones de personas son empleadas por cooperativas y estas aseguran la subsistencia de cerca de la mitad de la población en el mundo (OIT, 2). Datos recientes del World Cooperative Monitor, 2019 indican que las 3 millones de cooperativas con presencia en todo el mundo, 300 de ellas sostienen un volumen de negocio de 2,035 billones de dólares y dan empleo al $10 \%$ de la población mundial ocupada $(\mathrm{ACl}, 1)$.

La labor que se realiza por conducto de las cooperativas se ha hecho patente a través del reconocimiento que han realizado los organismos internacionales, como la Organización de las Naciones Unidas (ONU), designando el año 2012, como «Año Internacional de las Cooperativas» con el lema "Las empresas cooperativas ayudan a construir un mundo mejor». Con la celebración se establecieron tres objetivos, que no solo deben aplicarse en un año especial sino de manera permanente, como son: Crear mayor conciencia, promover el crecimiento, y establecer políticas adecuadas.

Dichos objetivos implican la reflexión sobre la contribución de las cooperativas al desarrollo económico y social, y al logro de los Objetivos de Desarrollo Sustentable, mediante estrategias que las impulsen, además de exhortar a los gobiernos y organismos reguladores a crear políticas y ordenamientos jurídicos que den certidumbre y sea el campo propicio para su desarrollo (ONU, 1).

No menos importante es la «Recomendación sobre la promoción de las cooperativas (R193)», donde la OIT reconoce a las diferentes for- 
mas cooperativas en su rol como creadoras de puestos de trabajo, la movilización de recursos, el fomento de las inversiones y en general su aporte a la economía y al desarrollo social (OIT, 1).

Las cooperativas han demostrado ampliamente su valía, ya que son organizaciones cuyo modelo empresarial sostenible contribuye al desarrollo regional, nacional e internacional (OIT, 2). Por ello, debe recordarse lo expresado por Stiglitz (50), «El desarrollo es un proceso que implica todos los aspectos de la sociedad, que precisa del esfuerzo de todos: mercados, gobiernos, ONG, cooperativas e instituciones sin ánimo de lucro».

No obstante los avances y el reconocimiento del que dan cuenta los organismos internacionales; es indiscutible que hace falta la acción conjunta y la intervención decidida del Estado en la construcción de estrategias y políticas públicas que revaloren el rol de las cooperativas y su mérito en el desarrollo social y económico, así como su contribución a la conservación ambiental en las regiones en las que tienen influencia.

\section{El cooperativismo en México}

Para describir la realidad del cooperativismo en México, en este apartado se explica cuál es la presencia de las cooperativas en las entidades federativas y su efecto en las actividades económicas, además de destacar las características de las tres clases de cooperativas, mencionando algunas con mayor relevancia.

\subsection{Las cooperativas en las entidades federativas}

De acuerdo con el Censo Económico 2014, del Instituto Nacional de Economía y Geografía (INEGI), en México el total de unidades económicas sumaron un total de 4,230,745, de las cuales 9,933 son sociedades cooperativas, lo que indica que tales unidades económicas representan el $2 \%$ del total, excluyendo a las personas físicas. Tal información revela que existe una limitada participación de las cooperativas en el espectro económico nacional. No obstante, debe recordarse que la importancia de estas sociedades no radica en su número, sino en efecto multiplicador de beneficios económicos y sociales entre las personas y sus comunidades.

Las cooperativas forman parte del sector social de la Economía, el que tiene su fundamento en el artículo 25 octavo párrafo de la Constitución Política de los Estados Unidos Mexicanos, precepto que señala lo siguiente: 
«La ley establecerá los mecanismos que faciliten la organización y la expansión de la actividad económica del sector social: de los ejidos, organizaciones de trabajadores, cooperativas, comunidades, empresas que pertenezcan mayoritaria o exclusivamente a los trabajadores $y$, en general, de todas las formas de organización social para la producción, distribución y consumo de bienes y servicios socialmente necesarios». (27-28).

Para cumplir con el ordenamiento constitucional, se requiere de instrumentos que permitan el desarrollo de las organizaciones del sector social. Para tal efecto, se cuenta con la Ley de la Economía Social y Solidaria, que tiene como objeto «fomentar el desarrollo, fortalecimiento y visibilidad de la actividad económica del sector social de la economía», además de impulsar a las organizaciones del sector social, para que pos su medio se generen fuentes empleo digno, se fortalezca la democracia y exista una equitativa distribución del ingreso y la generación de patrimonio social (Ley de la Economía Social y Solidaria, 2). Dicho ordenamiento, también contiene disposiciones que legitiman la actuación del Instituto Nacional de Economía Social (Ley de la Economía Social y Solidaria, 6), órgano que es responsable de llevar a cabo las acciones para ejecutar las acciones que den cumplimiento al objeto legal.

Cabe señalar que con el Censo Económico 2014, puede percibirse la magnitud y desarrollo del sector social, forjando evidencias sobre su desarrollo, fortalecimiento y visibilidad. Con dicha información se estableció que en dicho sector participan los sectores económicos: primario, industrial, comercial, financiero y de servicios, primordialmente en las actividades de pesca, agrícolas, mineras, de ahorro y préstamo y de consumo, donde se encuentran las cooperativas escolares.

Se confirmó que las unidades económicas de tipo cooperativo, se dedican en su mayoría a actividades del sector primario, financiero y comercio al por menor, observando que la mayor presencia cooperativa se encuentra entre las cooperativas dedicadas a la agricultura, cría y exportación de animales, aprovechamiento forestal, pesca y caza (Tabla 1). 
Tabla 1

Actividades de las cooperativas

\begin{tabular}{clc}
\hline Lugar & \multicolumn{1}{c}{ Descripción } & $\begin{array}{c}\text { Número de unidades } \\
\text { económicas }\end{array}$ \\
\hline 1 & $\begin{array}{l}\text { Agricultura, cría y explotación de animales, } \\
\text { aprovechamiento forestal, pesca y caza }\end{array}$ & 3.317 \\
\hline 2 & Servicios financieros y de seguros & 2,583 \\
\hline 3 & Comercio al por menor & 890 \\
\hline
\end{tabular}

Fuente: Censo Económico, 2014.

Las unidades económicas tienen presencia por todo el territorio nacional, pero de manera desigual, la heterogeneidad de actividades, numero, clase e influencia, revelan las diferencias que prevalecen en cada una de las 32 entidades federativas, las que pueden estar determinadas por las condiciones geográficas, la diversidad poblacional, el desarrollo económico, el apoyo de los gobiernos federal y local o la labor que se realiza a través de las organizaciones de la sociedad civil.

A través de los datos del INEGI, se pudo establecer la distribución geográfica de las cooperativas (la que fue desagregada del Censo Económico, 2014), destacando las 5 entidades federativas con un mayor número de cooperativas, las que son: Jalisco, Chiapas, Veracruz, Oaxaca y Guerrero. En contraste, las entidades con menor número de unidades económicas son: Aguascalientes, Tlaxcala, Coahuila, Quintana Roo y Morelos (Tabla 2). 


\section{Tabla 2}

\section{Cooperativas por Entidad Federativa}

\begin{tabular}{|c|c|c|}
\hline Entidad Federativa & Unidades económicas & $\begin{array}{c}\text { Posición nacional } \\
\text { (presencia de cooperativas } \\
\text { por entidad federativa }\end{array}$ \\
\hline Estados Unidos Mexicanos & 9,933 & \\
\hline Aguascalientes & 46 & 32 \\
\hline Baja California & 117 & 24 \\
\hline Baja California Sur & 280 & 15 \\
\hline Campeche & 332 & 11 \\
\hline Chiapas & 765 & 2 \\
\hline Chihuahua & 115 & 25 \\
\hline Coahuila de Zaragoza & 86 & 30 \\
\hline Colima & 114 & 26 \\
\hline Ciudad de México & 272 & 16 \\
\hline Durango & 113 & 27 \\
\hline Estado de México & 261 & 17 \\
\hline Guanajuato & 491 & 7 \\
\hline Guerrero & 630 & 5 \\
\hline Hidalgo & 203 & 20 \\
\hline Jalisco & 774 & 1 \\
\hline Michoacán de Ocampo & 539 & 6 \\
\hline Morelos & 103 & 28 \\
\hline Nayarit & 288 & 14 \\
\hline Nuevo León & 160 & 23 \\
\hline Oaxaca & 666 & 4 \\
\hline Puebla & 322 & 13 \\
\hline Querétaro & 187 & 21 \\
\hline Quintana Roo & 98 & 29 \\
\hline San Luis Potosí & 164 & 22 \\
\hline Sinaloa & 474 & 8 \\
\hline Sonora & 408 & 9 \\
\hline Tabasco & 358 & 10 \\
\hline Tamaulipas & 245 & 18 \\
\hline Tlaxcala & 47 & 31 \\
\hline Veracruz de Ignacio de la Llave & 719 & 3 \\
\hline Yucatán & 326 & 12 \\
\hline Zacatecas & 230 & 19 \\
\hline
\end{tabular}

Fuente: Censo Económico, 2014. 
Es preciso señalar que entre las cinco entidades federativas con un mayor número de cooperativas se encuentran Chiapas, Oaxaca y Guerrero que son Estados con altos niveles de pobreza. Es necesario indicar que de acuerdo con el Consejo Nacional de Evaluación de la Política de Desarrollo Social (CONEVAL), una persona se ubica en condición de pobreza, cuando presenta al menos una carencia social ${ }^{3}$, no tiene un ingreso suficiente para satisfacer sus necesidades y se encuentra en pobreza extrema; o bien, cuando presenta tres o más carencias sociales y no cuente con un ingreso suficiente para adquirir una canasta básica (CONEVAL, 1).

\subsection{Clases de cooperativas y sus características}

Las cooperativas son sociedades mercantiles, cuyo funcionamiento se formaliza a través de su constitución legal. Conforme al artículo 21 se contemplan tres clases de cooperativas (Ley General de Sociedades Cooperativas, 5):

- De consumidores de bienes y/o servicios,

- De productores de bienes y/o servicios y

- De ahorro y préstamo

Algunas características generales basadas en los ordenamientos legales, se enuncian enseguida:

- Son organizaciones del sector social,

- Son sociedades mercantiles,

- Cuentan con dos ordenamientos jurídicos: la Ley General de Sociedades Cooperativas y la Ley para Regular las Actividades de las Sociedades Cooperativas de Ahorro y Préstamo,

- Observan para su funcionamiento, principios y valores contenidos en Ley General de Sociedades Cooperativas,

- Son democráticas, pues se reconoce un voto por cada socio, independientemente de sus aportaciones,

- Se integran exclusivamente por personas físicas.

- Las cooperativas de producción y consumo se constituyen con por lo menos cinco socios mientras que las cooperativas de ahorro y préstamo con un mínimo de 25.

3 Son carencias sociales, la población con rezago educativo, población sin acceso a servicios de salud, sin acceso a calidad y espacios en la vivienda, carente de acceso a la alimentación y carente de acceso a servicios básicos de vivienda (CONEVAL, 1). 
- El régimen fiscal de las cooperativas se encuentra en la Ley del Impuesto Sobre la Renta, donde se contempla como no contribuyentes del impuesto a las cooperativas de ahorro y préstamo, así como las de consumo. Por su parte, las cooperativas de producción tributan como contribuyentes, pero se les asignan algunas exenciones y reducciones, principalmente para el sector primario (Lara Gómez, 260).

Como se ha visto, las cooperativas tienen presencia por todo el territorio nacional, no obstante, su potencial económico y participación en el mercado es heterogéneo, pues existen cooperativas que son ejemplo de sostenibilidad financiera y benefician de manera significativa a las regiones donde tienen presencia, mientras que otras son pequeñas y con bajo potencial financiero.

En este sentido, el sector que presenta mayor información estadística y financiera, es el que corresponde a las cooperativas de ahorro y préstamo, principalmente las que han sido autorizadas por la Comisión Bancaria y de Valores. La información estadística es vital para la toma de decisiones, por lo que contar con datos fiables y oportunos abona a su transparencia.

En los siguientes apartados se explicarán algunas características de las tres clases de cooperativas y sobre las organizaciones más representativas.

\subsubsection{LAS SOCIEDADES COOPERATIVAS DE CONSUMO}

Las cooperativas de consumo tienen como característica particular, que las actividades o transacciones que llevan a cabo, se realizan preferentemente entre los mismos socios. No obstante, la legislación cooperativa señala que pueden realizar adquisiciones terceros (no socios), con la condición de que tengan la opción de unirse a la sociedad. Una particularidad de las cooperativas de consumo, es que se encuentran liberadas del pago del Impuesto Sobre la Renta por ser catalogadas como personas morales no lucrativas (Lara Gómez, 260), lo que resulta muy beneficioso.

Algunos ejemplos sobresalientes pueden verse a través de organizaciones que se desempeñan en el sector agrícola, apoyando diversas ramas de la producción y de los servicios. Entre las que se puede mencionar a la Sociedad Cooperativa Agropecuaria del Distrito de Altar (SOCOADA), ubicada en el norte del país en Caborca, Sonora.

Por otras parte, en el Grullo, Jalisco se localiza la Sociedad Cooperativa Rural de Compra y Venta en Común y Comercialización El GruIlo S.C.L., que se exterioriza con el nombre comercial «Mi cooperativa 
de Consumo el Grullo» que es una comercializadora a través de la que se enajenan suministros necesarios para el sector agrícola y ganadero, pero también se ofertan productos de consumo familiar.

Otras cooperativas en este sector son las que se integran en las escuelas de educación básica, pero también existen otras dedicadas al desarrollo local, las que se crean para detonar el progreso de las comunidades, principalmente las que se encuentran en regiones marginadas, creando alternativas de desarrollo a través de las actividades de consumo en común.

La creación de cooperativas de consumo resulta benéfico para la sociedad, ya que al realizar compras conjuntas, se reduce el costo y es posible vender los productos a un precio razonable, inclusive por debajo del mercado, ya que no se persigue el lucro, sino cumplir con la finalidad económica que brinde beneficios sociales a los cooperativistas y a la comunidad. Cooperativas como SOCOADA o la ubicada en el Grullo, Jalisco, han demostrado que a través del consumo conjunto es posible beneficiar la economía de un número importante de personas, pues tales sociedades actúan como reguladoras de precios en sus regiones; por lo que experiencias de este tipo merecen ser difundidas y replicadas.

\subsubsection{LAS SOCIEDADES COOPERATIVAS DE PRODUCCIÓN}

En lo que se refiere a las cooperativas de producción, sus actividades se desarrollan principalmente en el sector industrial, agrícola, pesquero y de servicios. Como se ha dicho, esta clase de organización societaria es contribuyente del Impuesto Sobre la Renta, pero con algunas excepciones para el sector primario, lo que hace que las cooperativas de producción de servicios y otras actividades diferentes a las del sector primario prácticamente no cuenten con beneficios y tributen de la misma forma que las empresas de capitales (Lara Gómez, 260).

Entre las cooperativas de producción con mayor tradición y reconocimiento se encuentra la cooperativa Manufacturera de Cementos Pórtland La Cruz Azul, SCL, que es una organización representativa del sector cooperativo industrial. Entre las características más importantes de dicha sociedad se puede mencionar que, fue fundada desde 1881 por un inversionista inglés y transformada en cooperativa en 1934, cuando los trabajadores promovieron su adjudicación, apoyados en la Ley de Expropiación por Causa de Utilidad Pública vigente en el Estado de Hidalgo. Hoy la cooperativa "La Cruz Azul», es una influyente empresa de la Industria del Cemento, con múltiples reconocimientos y certificaciones nacionales e internacionales por la comercialización de cemento Pórtland (Cooperativa La Cruz Azul, 1). 
Otra de las cooperativas de gran presencia en México es la «Sociedad Cooperativa Trabajadores de Pascual, S.C.L». que es una industria refresquera, que tiene sus raíces en una sociedad anónima fundada en 1940, y luego convertida en cooperativa, como resultado de un movimiento de huelga consecuencia de un conflicto laboral, donde los trabajadores tomaron posesión de la empresa como pago por sus sueldos e indemnizaciones laborales, constituyendo la cooperativa el 27 de mayo de 1985.

Existen otros ejemplos de cooperativas de producción, que se han desarrollado favorablemente en diversos sectores, como en la agricultura, la ganadería, la pesca, el turismo, y en general en diversas actividades de los servicios.

Como se ha manifestado, esta clase de cooperativas son una alternativa para la promoción del bien común, así como para detonar iniciativas productivas en beneficio de la sociedad. No obstante, las cooperativas de producción de servicios se han utilizado indebidamente por empresarios sin escrúpulos, para evitar las cargas laborales y fiscales, principalmente en lo relativo a las aportaciones de seguridad social. A través de las cooperativas, se han venido fomentando prácticas que promueven el trabajo precario por medio de la subcontratación (Lara Gómez, 93).

\subsubsection{LAS SOCIEDADES COOPERATIVAS DE AHORRO Y PRÉSTAMO}

El antecedente de las cooperativas de ahorro y préstamo son las cajas populares, entidades que fueron fundadas en 1951. Fue hasta 1991, que fueron reconocidas en una legislación federal y en 1994, con la publicación de la Ley General de Sociedades Cooperativas, se incluyó la actividad financiera de las cooperativas a través de las cooperativas de consumo, lo que dio la pauta para que las cajas populares iniciaran un proceso de regularización. Posteriormente, en 2001 se agregó una tercera clase de cooperativa, la de ahorro y préstamo. Actualmente, se reconoce a las cooperativas como parte del Sistema Financiero Mexicano, con personalidad jurídica propia y capacidad para realizar intermediación financiera, todo ello fue posible, después de un largo proceso de autorización por parte de la Comisión Nacional Bancaria y de Valores, la participación de organismos internacionales y el Estado para profesionalizar la actividad de intermediación (Lara Gómez, Pérez Sosa y Hurtado Maldonado, 128-129).

El proceso de regulación estuvo plagado de situaciones positivas y negativas para el sector, algunas cooperativas de ahorro y préstamo se consolidaron financiera y estructuralmente, pero otras sufrieron procesos de fusión y algunas más desaparecieron al entrar en liquidación. 
No obstante los avances, puede decirse que la legislación actual (Ley para Regular las Actividades de las Sociedades Cooperativas de Ahorro y Préstamo) no impulsa a las cooperativas pequeñas, las que han sido catalogadas como de nivel básico, debido a que la autorización, supervisión y fondos de protección, son exclusivas de las cooperativas con mayor grado de sofisticación, es decir, las que se han clasificado en los niveles del 1 al IV. De manera que son las cooperativas autorizadas, las que pueden ofrecer a sus socios fondos de protección en caso de procesos de quiebra. Además de que es posible conocer su situación financiera, ya que están obligadas a entregar información a la Comisión Nacional Bancaria y de Valores, así como al Fideicomiso Fondo de Supervisión Auxiliar de Sociedades Cooperativas de Ahorro y Préstamo y de Protección a sus Ahorradores (FOCOOP) (Lara Gómez, Pérez Sosa y Hurtado Maldonado, 128).

En este sentido, de acuerdo con información del FOCOOP a diciembre de 2019, en México se cuentan un total de 803 entidades, de entre ellas 156 se encuentran autorizadas por la CNBV y son las que poseen la mayor cantidad de activos del sector, mientras que 517 están clasificadas como de nivel básico. El total de personas asociadas a una cooperativa de ahorro y préstamo representan más de 8.5 millones; de entre ellas más de 7.3 millones son socias de una cooperativa autorizada por la CNBV (FOCOOP, 4).

Algunos datos relevantes indican que las entidades autorizadas poseen el $86 \%$ de los socios, mientras que las 517 cooperativas de nivel básico solo integran el 3\% del total de socios. Es importante mencionar que en cuanto a montos de activos, el $97 \%$ se encuentra en las entidades autorizadas (FOCOOP, 2). No obstante, que los datos ponen en desventaja a las cooperativas de nivel básico, dichas sociedades hacen una importante labor en las comunidades con altos índices de rezago económico y social, pues representan la única alternativa para que las personas tengan acceso a servicios financieros, lo que implica un importante aporte a la inclusión financiera. Por tanto, debe incentivarse la consolidación de las cooperativas de nivel básico, a través de la modificación de las leyes, así como del apoyo técnico y financiero por parte del Estado, para fortalecer su operación y minimizar el riesgo.

\section{Retos y perspectivas}

La realidad que estamos viviendo nos enfrenta a retos inéditos, que requieren de soluciones urgentes para atender los problemas de siempre y los que se han sumado por los efectos de la emergencia sanitaria 
que ha originado el surgimiento de la enfermedad infecciosa COVID-19; la que ha sido catalogada como pandemia global y que ha traído consecuencias nocivas para las personas y la economía. Los efectos de la pandemia han visibilizado las grandes carencias de infraestructura, personal y capacidad de atención en el sector de la salud; con lo que se ha evidenciado la debilidad de las economías emergentes, que han sufrido el descenso sostenido de las percepciones por ingresos fiscales, por turismo, remesas, petróleo, entre otras fuentes de ingreso que tradicionalmente mantenían a flote a las naciones como la mexicana.

Las problemáticas que han emergido a la par de la pandemia pueden explicarse a partir de las necesidades que se encuentran presentes entre las familias, pues con la nueva situación, se ha mermado el ingreso entre la población que ha sufrido de la pérdida de los puestos de trabajo. Es innegable que también han surgido conflictos intrafamiliares por la convivencia diaria y por la necesidad de hacer ajustes al nivel de vida al que cada familia está acostumbrado. A esta nueva realidad, se han sumado los incrementos en el costo de los servicios básicos, los alimentos y los costos para continuar con la educación, que exige tener acceso a internet y poseer un dispositivo adecuado para recibir las clases.

Los estragos de una enfermedad que seguramente se quedará entre nosotros son incalculables, no solo por el detrimento económico, sino por las secuelas que está dejando entre las personas, quienes requerirán de atención médica y psicológica que no será posible sufragar en las condiciones presentes, ya que el Estado se ha visto rebasado ante la demanda de servicios y su disponibilidad de recursos públicos.

Desafortunadamente, los sectores de población pobre y los doblemente vulnerables por situaciones de marginación y pobreza, han sido las que en su mayoría han resentido las consecuencias de la COVID-19. Pues, de acuerdo con Noticias ONU (1), México ocupa el cuarto lugar de contagios entre los países de América Latina, pero potencialmente en la región existe riesgo de contagio de 142 millones de personas, lo que se acentúa por la presencia de tres indicadores: la falta de acceso a agua potable, el uso de combustibles nocivos dentro de los hogares y la desnutrición.

Por su parte, en el Foro Económico Mundial se afirma que; desde «La Gran depresión de 1929», el mundo no había vivido una situación similar, la que se ha calificado como catastrófica, ya que en México, se ha afectado seriamente el sector industrial, el turístico, la recepción de remesas provenientes del extranjero, a lo que se ha sumado la caída en el precio de los minerales y del petróleo (INFOBAE, 1).

Entonces, ¿cuáles son los retos para las cooperativas ante esta situación que resulta inédita? Como ya se ha descrito, las cooperati- 
vas ofrecen múltiples beneficios para las personas que se asocian en torno a un objetivo común, por lo que deben afrontarse diversos retos para sostener las experiencias locales, permaneciendo en el mercado y dando continuidad a los beneficios sociales.

Los retos que el sector cooperativo debe atender y las perspectivas vistas como una visión del futuro, se expresan a través del trabajo que debe desarrollarse desde el Estado, la sociedad civil y las propias cooperativas. Algunos de los temas que deberán abordarse, se mencionan enseguida:

1. Eficiencia Financiera. Mantener la sostenibilidad financiera, es uno de los desafíos que deberán atender las cooperativas para permanecer en el mercado. En este tenor, debe recordarse que la experiencia de la Banca cooperativa ha mostrado que estas organizaciones pudieron sortear las debacles financieras que dañaron fuertemente a la banca tradicional.

Debe señalarse que a pesar del cierre de diversas actividades económicas, como una de las consecuencias de la pandemia, las cooperativas han continuado prestando servicios, produciendo bienes, promoviendo el consumo en común y proporcionando trabajo, lo que tiene un significado alentador sobre la permanencia de estas organizaciones, como actores clave en la recuperación económica del país.

2. Legislación para el impulso del sector social. Mediante los ordenamientos jurídicos idóneos y la puesta en marcha de políticas públicas, el Estado debe cumplir plenamente el mandato constitucional que dicta establecer mecanismos para la promoción de las organizaciones y la expansión del sector social. De tal forma que, deben reformarse las leyes que restringen la expansión del sector, por ejemplo, eliminar la limitación contenida en la Ley General de Sociedades Cooperativas que señala que únicamente podrán asociarse personas físicas, dejando fuera a personas morales que también realizan actividades propias del sector social.

Asimismo, es necesario incorporar infracciones y sanciones que castiguen la simulación y el uso indebido de las cooperativas, ya que de no hacerlo, prevalecerá la desconfianza en la gestión y seguridad de estas organizaciones.

3. Inclusión financiera. Las cooperativas de ahorro y préstamo, deben encabezar los esfuerzos de inclusión financiera en las regiones con mayor rezago en el tema, de manera que las alianzas estratégicas son fundamentales, principalmente con el Estado, 
a efecto de participar en los programas gubernamentales que se promueven a través del Banco del Bienestar y otros organismos del Estado.

4. Participación activa en el mercado. Las cooperativas deben participar en el mercado con las mismas condiciones de igualdad que las empresas privadas. De manera que, a partir de la iniciativa de las cooperativas y en congruencia con las políticas públicas que promueven el dinamismo económico, debe procurarse la participación de las cooperativas reconociendo la idoneidad de su modelo social e incentivando su actividad económica mediante incentivos tributarios.

5. Consumo y producción en común. Impulsar las diferentes formas jurídicas e iniciativas comunitarias, que promueven la producción en el sector primario, así como el consumo común. En este sentido, la sociedad civil organizada, debe considerar la creación de cooperativas de consumo, ya que a través de ellas se ofrecen ventajas, principalmente en el campo tributario que se expresa con la exoneración del Impuesto Sobre la Renta por los ingresos que la cooperativa perciba por su actividad.

6. Visibilizar al sector cooperativo. Hacer perceptibles los logros que se consolidan mediante la acción cooperativa, la producción de información estadística fiable y actualizada, con la que sea posible medir el impacto económico de las cooperativas en los indicadores nacionales. En este punto, resulta necesaria la incorporación de estudiosos e investigadores en temas cooperativos, para que a través de sus productos académicos se difundan las experiencias, aprendizajes y se generen conocimientos útiles para la difusión, consolidación y permanencia de las cooperativas.

Con información y conocimiento es factible conectar a las cooperativas con las comunidades e identificar las regiones geográficas con mayor rezago y que requieren de atención urgente en temas de inclusión financiera, empresas de inserción, redes de producción-consumo, entre otras iniciativas que surgen en el sector social.

7. Promoción de la cultura cooperativa. La cultura expresada por las tradiciones, costumbre y prácticas compartidas en una comunidad, deben ser fortalecidas con la solidaridad, ayuda mutua y bien común, lo que permitirá alimentar nuevas prácticas en beneficio de la sociedad. Es por ello que, deben introducirse programas que fomenten la cultura y la educación cooperativa entre los menores y fomentarla entre los adolescentes y adultos. Poseer educación financiera, favorece una sana convivencia 
y coadyuva a los procesos de inclusión financiera entre la población, lo que implican el incremento de capacidades para tomar decisiones acertadas en cuanto al ahorro, el crédito y en general el consumo.

8. Fortalecimiento integral del sector cooperativo. Como se ha comentado, las cooperativas tienen una importante presencia en el número de unidades económicas en los sectores de la agricultura, cría y explotación de animales, aprovechamiento forestal, pesca y caza, así como en los servicios financieros, lo que debe potenciarse para favorecer la producción de alimentos y la inclusión financiera de los mexicanos que aún tienen limitaciones de crédito.

9. Contribución de otros interlocutores. Para el óptimo desarrollo del sector social de la economía, es imperioso que se conjunten esfuerzos de los diferentes participantes de la sociedad: Las personas, el Estado, las organizaciones no gubernamentales y las Universidades, todos ellos cumplen con funciones centrales para el desarrollo del sector y contribuyen con sus iniciativas, políticas públicas, así como la generación del conocimiento y la enseñanza a que la realidad que se vive en México sea cada día mejor.

Los retos descritos incluyen la visión del futuro que se requiere, lo que implica que las personas se involucren y comprometan con los objetivos que permitan abatir los importantes rezagos, que históricamente se han venido padeciendo en México. Por lo que las cooperativas están llamadas a ser las protagonistas de un cambio que traiga beneficios y justicia para todos. Por su parte, el Gobierno cumplirá con su función en tanto actué con ética y responsabilidad, erradicando la problemática que surge con la corrupción. Los organismos no gubernamentales incidirán positivamente en las políticas públicas y en el desarrollo de los puebles, proporcionando propuestas viables y dando voz a los que han sido rezagados del desarrollo. Las Universidades, deben cumplir con su finalidad social, siendo la fuente de conocimiento que permite sistematizar y replicar las prácticas solidarias que han influido positivamente en la cotidianidad de las personas, principalmente entre las más vulnerables.

\section{Conclusiones}

Las propuestas solidarias que han sido reconocidas por sus beneficios entre la sociedad, han emergido en la más aguda necesidad, generando la unión de las personas con un espíritu transformador de la realidad. 
Con los eventos recientes que modifican la forma de vida en sociedad, la economía y en general los procesos de interacción social, resulta inaplazable revalorar las fórmulas que ha demostrado eficacia en la atención de los problemas comunes, pero que no han sido priorizadas por los gobiernos, como una estrategia que dé respuesta a las demandas de las mayorías, atendiendo desde una perspectiva de la solidaridad y del bien común las problemáticas de los que hoy se encuentra en situación de desventaja económica y/o social.

Retomar los Objetivos de Desarrollo Sostenible, desde una perspectiva local, contribuyen a reflexionar sobre la vigencia del modelo económico dominante, creando conciencia en lo verdaderamente importante, que es el ser humano y no la acumulación de riqueza. Es el momento en el que en el Estado mexicano se aborden los temas prioritarios con un enfoque de promoción del crecimiento económico que incluya a todos, promoviendo la igualdad y la justicia, a partir de políticas públicas y ordenamientos jurídicos que respeten los derechos fundamentales y cumpla el mandato constitucional que dicta la función del Estado como promotor de la organización y expansión del sector social de la economía.

\section{Bibliografía}

ACl, 2018. Datos y Cifras. Acceso en línea el 12/06/2020.

Censo Económico, 2014. Microdatos del Instituto Nacional de Geografía y Estadística (INEGI). Acceso en línea el 10/01/2020.

CONEVAL, 2015. Carencias sociales 2015 y su comparativo con la serie 20102014. Acceso en línea el 12/06/2020.

Cooperativa la Cruz Azul, 2020. Historia. Acceso en línea el 12/03/2020.

FOCOOP, 2019. Fideicomiso del Fondo de Supervisión Auxiliar de Sociedades Cooperativas de Ahorro y Préstamo y de Protección a sus Ahorradores.

INFOBAE, 2020. Seis efectos catastróficos del coronavirus en la economía mexicana, según el Foro Económico Mundial. Acceso en línea el 24/08/2020.

LARA Gómez, G. La equidad horizontal en la tributación de las cooperativas en México. Boletín de la Asociación Internacional de Derecho Cooperativo = International Association of Cooperative Law Journal. No. 53, 2018, pp. 251-273.

LARA Gómez, Graciela, Pérez Sosa, Felipe Abelardo y Hurtado Maldonado, Jesús. Finanzas Populares en México. México: Fontamara, 2017.

Lara Gómez, Graciela. Cooperativas y prácticas laborales en México. Revista CIFE: Lecturas de Economía Social, 2019. 21(35), 81-104. DOI: https://doi. org/10.15332/22484914.5371

MARTínez ChARTERINA, Alejandro. Las cooperativas y su acción sobre la sociedad. REVESCO N. ${ }^{\circ} 117$-monográfico: Las sociedades cooperativas construyen un mundo mejor, 2016 pp. 34-49. ISSN: 1885-8031. 
Mi cooperativa de consumo El Grullo, 2020. Quiénes somos. Acceso en línea el $12 / 06 / 2020$.

NotiCIAS ONU, 2020. COVID, hambre, pobreza y desigualdad: la combinación mortal que enfrenta América Latina. Acceso en línea el 24/08/2020.

OIT, 2002. R193-Recomendación sobre la promoción de las cooperativas, 2002 (núm. 193). Organización Internacional del Trabajo. Acceso en línea el $14 / 06 / 2020$.

OIT, 2015. Las cooperativas y los objetivos de desarrollo sostenible, Debate sobre el desarrollo después de 2015. Organización Internacional del Trabajo. Acceso en línea el 12/06/2020.

ONU, 2012. 2012 Año Internacional de las cooperativas. Acceso en línea el $12 / 06 / 2020$.

Sociedad Cooperativa Trabajadores de Pascual, S.C.L., 2020. ¿Quiénes somos? Acceso en línea el 12/03/2020.

SOCOADA, 2020. SOCOADA, S. C. L. Sociedad Cooperativa Agropecuaria del Distrito De Altar, S. C. L. Acceso en línea el 12/06/2020.

Stiglitz, Joseph. El precio de la desigualdad. México: Taurus, 2012.

\section{Anexo legislativo}

Constitución política de los estados unidos mexicanos. Diario Oficial del 4 de agosto de 1934 (archivos de la Cámara de Diputados). Acceso en línea el 23/07/2020.

Ley de la economía social y solidaria, Reglamentaria del Párrafo Octavo del Artículo 25 de la Constitución Política de los Estados Unidos Mexicanos, En lo referente al sector social de la economía. Diario Oficial del 23 de mayo de 2012. Acceso en línea el 20/07/2020.

Ley general de sociedades cooperativas. Diario Oficial del 4 de agosto de 1934 (archivos de la Cámara de Diputados). Acceso en línea el 23/07/2020. 


\section{Derechos de autor}

La revista Deusto Estudios Cooperativos es una revista de acceso abierto lo que significa que es de libre acceso en su integridad inmediatamente después de la publicación de cada número. Se permite su lectura, la búsqueda, descarga, distribución y reutilización legal en cualquier tipo de soporte sólo para fines no comerciales y según lo previsto por la ley; sin la previa autorización de la Editorial (Universidad de Deusto) o el autor, siempre que la obra original sea debidamente citada (número, año, páginas y DOI si procede) y cualquier cambio en el original esté claramente indicado.

\section{Copyright}

The Deusto Journal of Cooperative Studies is an Open Access journal which means that it is free for full and immediate access, reading, search, download, distribution, and lawful reuse in any medium only for non-commercial purposes, without prior permission from the Publisher or the author; provided the original work is properly cited and any changes to the original are clearly indicated. 